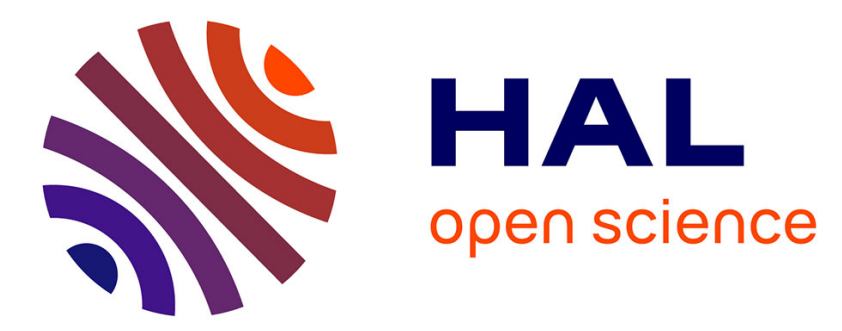

\title{
Anthropometry, breast cancer and menopausal status: use of repeated measurements over 10 years of follow-up-results of the French E3N women's cohort study.
}

Bertrand Tehard, Petra H. Lahmann, Elio Riboli, Françoise Clavel-Chapelon

\section{To cite this version:}

Bertrand Tehard, Petra H. Lahmann, Elio Riboli, Françoise Clavel-Chapelon. Anthropometry, breast cancer and menopausal status: use of repeated measurements over 10 years of follow-up-results of the French E3N women's cohort study.. International Journal of Cancer, 2004, 111 (2), pp.264-9. 10.1002/ijc.20213 . inserm-00123308

\section{HAL Id: inserm-00123308 https://www.hal.inserm.fr/inserm-00123308}

Submitted on 4 Sep 2009

HAL is a multi-disciplinary open access archive for the deposit and dissemination of scientific research documents, whether they are published or not. The documents may come from teaching and research institutions in France or abroad, or from public or private research centers.
L'archive ouverte pluridisciplinaire HAL, est destinée au dépôt et à la diffusion de documents scientifiques de niveau recherche, publiés ou non, émanant des établissements d'enseignement et de recherche français ou étrangers, des laboratoires publics ou privés. 


\title{
Anthropometry, breast cancer and menopausal status: use of repeated measurements over 10 years of follow-up - Results of the French E3N women's cohort study
}

\author{
Bertrand Tehard ${ }^{1}$, Petra H. Lahmann², Elio Riboli ${ }^{3}$, Françoise Clavel-Chapelon ${ }^{*}$ and the E3N \\ Group
}

${ }^{1}$ Equipe E3N-IGR, INSERM XR 521, Institut Gustave Roussy, Villejuif, France. ${ }^{2}$ Department of Epidemiology, German Institute of Human Nutrition, Potsdam-Rehbrücke, Germany. ${ }^{3}$ International Agency for Research on Cancer, Lyon, France.

Key words: BMI; weight; breast cancer; methodological issue; HRT use; cohort study

The association between weight, BMI and breast cancer was analyzed on 94,805 women of the E3N cohort according to their menopausal status. Seven hundred eighty-six incidentinvasive premenopausal breast cancers and 1,522 incident invasive postmenopausal breast cancers occurred during a mean follow-up of 9.7 years. Weight and BMI were updated every 24 months and considered as time-dependent variables. Data were analyzed using multivariate Cox proportional hazards models. Trend RRs of premenopausal breast cancer were $0.97(0.92-1.01)$ for a $5 \mathrm{~kg}$ increase in weight and $0.96(0.91-1.01)$ for a $2 \mathrm{~kg} / \mathrm{m} 2$ increase in BMI, adjusted for other known risk factors. Opposite trend RRs were found after menopause: 1.05 (1.02-1.08) for weight and 1.06 (1.02-1.09) for BMI, respectively, for similar increases. Women with a BMI of over $30 \mathrm{~kg} / \mathrm{m} 2 \mathrm{had}$ a RR of premenopausal breast cancer of $0.66(0.40-1.10)$ compared to those with a BMI of between 18.5 and $25 \mathrm{~kg} / \mathrm{m} 2$. Postmenopausal women with a BMI of over $30 \mathrm{~kg} / \mathrm{m} 2$ had a RR of breast cancer of $1.23(1.00-1.59)$. The increase in risk of postmenopausal breast cancer with increased weight or BMI was similar whatever the HRT used, although the point estimates were higher in HRT users. We strongly recommend to use anthropometric measurements updated during follow-up to assess the effect of weight, BMI on breast cancer risk.

Literature reviews ${ }^{1-3}$ and meta-analysis ${ }^{4}$ showed evidence of a positive relation between overweight or obesity and postmenopausal breast cancer and a possible inverse relation with premenopausal breast cancer.

Hypothesizing that overweight affects hormonal metabolism throughout life, and given the sharp increase in obesity in most Western countries, our aim was to examine weight and body mass index (BMI) in relation to pre- and post-menopausal breast cancer occurrence. Moreover, as weight and BMI might vary through life, especially at menopause, we considered it essential to analyze them as time-dependent variables allowing adequate control of their variations. Only a few cohort studies ${ }^{2,5,6}$ have analyzed weight and BMI over time and they limited their investigation of variations in weight or BMI to a comparison between measurements made at the beginning and end of follow-up. In order to avoid errors due to risk exposure only measured at enrollment in the cohort study, i.e., possibly far from the event of interest, we modeled breast cancer risk using anthropometric measurements regularly updated.

E3N (Etude Epidémiologique de femmes de la Mutuelle Générale de l'Education Nationale), a prospective cohort study on French women, offered the opportunity to study the evolution of weight and BMI in relation to pre- and post-menopausal breast cancer occurrence over a 10-year follow-up period, during which weight was recorded every 2 years.

Grant sponsor: F. Clavel-Chapelon, French League against Cancer; Grant sponsor: European Community; Grant sponsor: 3M Company; Grant sponsor: Mutuelle Générale de l’Education Nationale

\footnotetext{
"Correspondence to: Equipe E3N-IGR, INSERM XR 521 Institut Gustave Roussy, 39 rue Camille Desmoulins 94805 Villejuif Cedex, France. Fax:+33-1-42-11-40-00. E-mail: clavel@igr.fr
} 


\section{Material and methods}

E3N's main objective is to investigate risk factors for cancer. The design of the study has been described elsewhere.7 Briefly, the cohort consists of 98,997 women living in France, who were insured with a national health insurance scheme primarily covering teachers. They were aged 40-65 years at enrollment (between June 1990 and November 1991) after replying to a baseline questionnaire. The E3N cohort is the French part of the European Prospective Investigation on Cancer (EPIC8).

Since baseline, participants were followed by self-administered questionnaires sent out approximately every 24 months. We analyzed the variables on weight as self-reported in each of the first 5 questionnaires and on height as recorded at baseline.

Menopause was recorded in each follow-up questionnaire. To ensure that the constructed menopause variables were as accurate as possible, the whole set of answers on date and type of menopause (natural or the result of bilateral oophorectomy, chemotherapy, radiotherapy or other treatment), date of last menstruation, date of start of menopausal symptoms and date of hysterectomy, if appropriate, were taken into account. Postmenopause was defined as the cessation of periods for natural reasons or due to radiation, chemotherapy or surgery (total oophorectomy). The menopausal status of 24,910 women changed during follow-up. Women contributed to the premenopausal group for the period between enrollment and onset of menopause and then to the postmenopausal group until the end of follow-up. Women with undefined menopausal status (for instance, because of continuous use of hormonal treatments or hysterectomy with no additional information on oophorectomy) were not considered in the analysis $(n=1790)$ nor were those who had never menstruated $(n=$ 4). Women who had reported a cancer other than a basal cell carcinoma at enrollment were excluded $(n=2,398)$.

All questionnaires asked participants whether breast cancer had been diagnosed, requesting the addresses of their physicians and permission to contact them. Information on nonrespondents was obtained from the MGEN file on the reimbursement of hospital fees, enabling additional breast cancer cases to be found.

Follow-up time is considered between return of the baseline questionnaire and June 28, 2000, the date at which the 6th questionnaire was sent out. Mean follow-up is 9.7 years ( $\operatorname{Std}=1.2$ years). The present analysis is based on the follow-up of a total sample of 94,805 women who between them reported 2,308 breast cancers, consisting of 786 premenopausal and 1,522 postmenopausal breast cancers.

Data were analyzed using Cox proportional hazards models with age as the time scale. The adjustment variables taken into account were age at menarche $(<12,12,13$ and $\geq 14)$, age at first birth $(<23,23-25,26-29$ and $\geq 30)$, parity $(0,1-3$ and $\geq 4)$, history of breast cancer in first degree relatives (yes/no), history of benign breast disease (yes/no), alcohol consumption (drink(s) per week, $0,<1$ and $\geq 1$ ), number of years at school $(0,1$ $5,6-9,10-13,14-15$ and $\geq 16$ ) and ever married (yes/no). Additional adjustments were performed on quartiles of physical activity and height. Use of HRT was tested as a potential effect modifier. Weight and BMI were updated and introduced in the models as time-dependent variables. Women with missing values on weight or BMI were excluded from calculation during the time for which these values were missing. Weight and BMI were considered as continuous variables and categorized in quartiles according to their distributionin the replies to the first questionnaire. We also considered WHO cut-off points for the BMI. ${ }^{9}$

All analyses were performed with $\mathrm{SAS}^{\circledR}$ Software. ${ }^{10}$

\section{Results}

The anthropometric characteristics of cases and noncases, based on the replies to each questionnaire, were compared (Table I). Marginal differences were observed between cases and noncases. Among premenopausal women, cases were slightly leaner than noncases, but mean differences on weight and BMI did not exceed $1.6 \mathrm{~kg}$ and $0.7 \mathrm{~kg} / \mathrm{m}^{2}$ respectively. In contrast, among postmenopausal women, cases were slightly heavier than noncases with maximum mean differences lower than $1.8 \mathrm{~kg}$ and $0.5 \mathrm{~kg} / \mathrm{m}^{2}$. 
Table 1: Anthropometric characteristics of breast cancer cases ${ }^{1}$ and non-cases in the E3N cohort by menopausal status* at the time of each questionnaire.

\begin{tabular}{|c|c|c|c|c|c|c|c|c|c|c|}
\hline \multirow{2}{*}{ Variable } & \multicolumn{2}{|c|}{ First questionnaire } & \multicolumn{2}{|c|}{ Second questionnaire } & \multicolumn{2}{|c|}{ Third questionnaire } & \multicolumn{2}{|c|}{ Fourth questionnaire } & \multicolumn{2}{|c|}{ Fifth questionnaire } \\
\hline & $N$ & Mean $(\mathrm{Std})$ & $N$ & Mean (Std) & $N$ & Mean $(\mathrm{Std})$ & $N$ & Mean $(\mathrm{Std})$ & $N$ & Mean $(\mathrm{Std})$ \\
\hline \multicolumn{11}{|c|}{ Premenopausal women } \\
\hline \multicolumn{11}{|c|}{ Weight $(\mathrm{kg})$} \\
\hline Cases & 181 & $59.3(9.9)$ & 153 & $58.6(8.9)$ & 120 & $59.1(8.1)$ & 104 & $59.1(9.6)$ & 134 & $59.2(8.1)^{*}$ \\
\hline Noncases & 48,963 & $58.2(8.7)$ & 36,485 & $58.8(9.0)$ & 26,357 & $58.9(8.7)$ & 19,896 & $59.8(9.5)$ & 20,043 & $60.8(10.1)$ \\
\hline \multicolumn{11}{|l|}{ BMI $\left(\mathrm{kg} / \mathrm{m}^{2}\right)$} \\
\hline Cases & 181 & $22.3(3.5)$ & 153 & $22.2(3.1)$ & 120 & $22.4(2.6)$ & 104 & $22.4(3.1)$ & 134 & $22.4(2.7) \dagger^{*}$ \\
\hline Noncases & 48,963 & $22.1(3.0)$ & 36,485 & $22.3(3.1)$ & 26,357 & $22.4(3.0)$ & 19,896 & $22.6(3.3)$ & 20,043 & $23.1(3.6)$ \\
\hline \multicolumn{11}{|c|}{ Post-menopausal women } \\
\hline \multicolumn{11}{|c|}{ Weight (kg) } \\
\hline Cases & 156 & $60.3(9.8)$ & 206 & $61.8(10.2) \dagger$ & 150 & $62.1(11.1) \dagger$ & 239 & $61.8(9.7)$ & 560 & $62.0(9.7)$ \\
\hline Noncases & 41,271 & $60.0(9.4)$ & 41,469 & $60.4(9.7)$ & 38,117 & $60.3(9.2)$ & 41,215 & $61.0(9.8)$ & 61,847 & $61.8(10.3)$ \\
\hline \multicolumn{11}{|l|}{ BMI $\left(\mathrm{kg} / \mathrm{m}^{2}\right)$} \\
\hline Cases & 156 & $23.3(3.3)$ & 206 & $23.6(3.6)$ & 150 & $23.6(3.9)$ & 239 & $23.7(3.6)$ & 560 & $23.7(3.5)$ \\
\hline Noncases & 41,271 & $23.1(3.6)$ & 41,469 & $23.2(3.4)$ & 38,117 & $23.1(3.3)$ & 41,215 & $23.4(3.5)$ & 61,847 & $23.7(3.7)$ \\
\hline
\end{tabular}

${ }^{1}$ Incident cases occurring between two consecutive questionnaires

* Menopausal status at enrolment in the study

$\dagger$ : p-value $<0.05$.

Variations in BMI for pre- and post-menopausal women during follow-up were studied. A positive trend was seen in BMI gain since enrollment in the study in 1990 both in the premenopausal (Fig. 1) and postmenopausal (Fig. 2) groups, whatever the age category. After menopause, the increase in

BMI was apparent, though it was more pronounced in the 2 younger birth cohorts.

Figure 1: B M I variations during follow-up, according to age categories at inclusion, for premenopausal women of the $\mathbf{E} \mathbf{N}$ cohort.

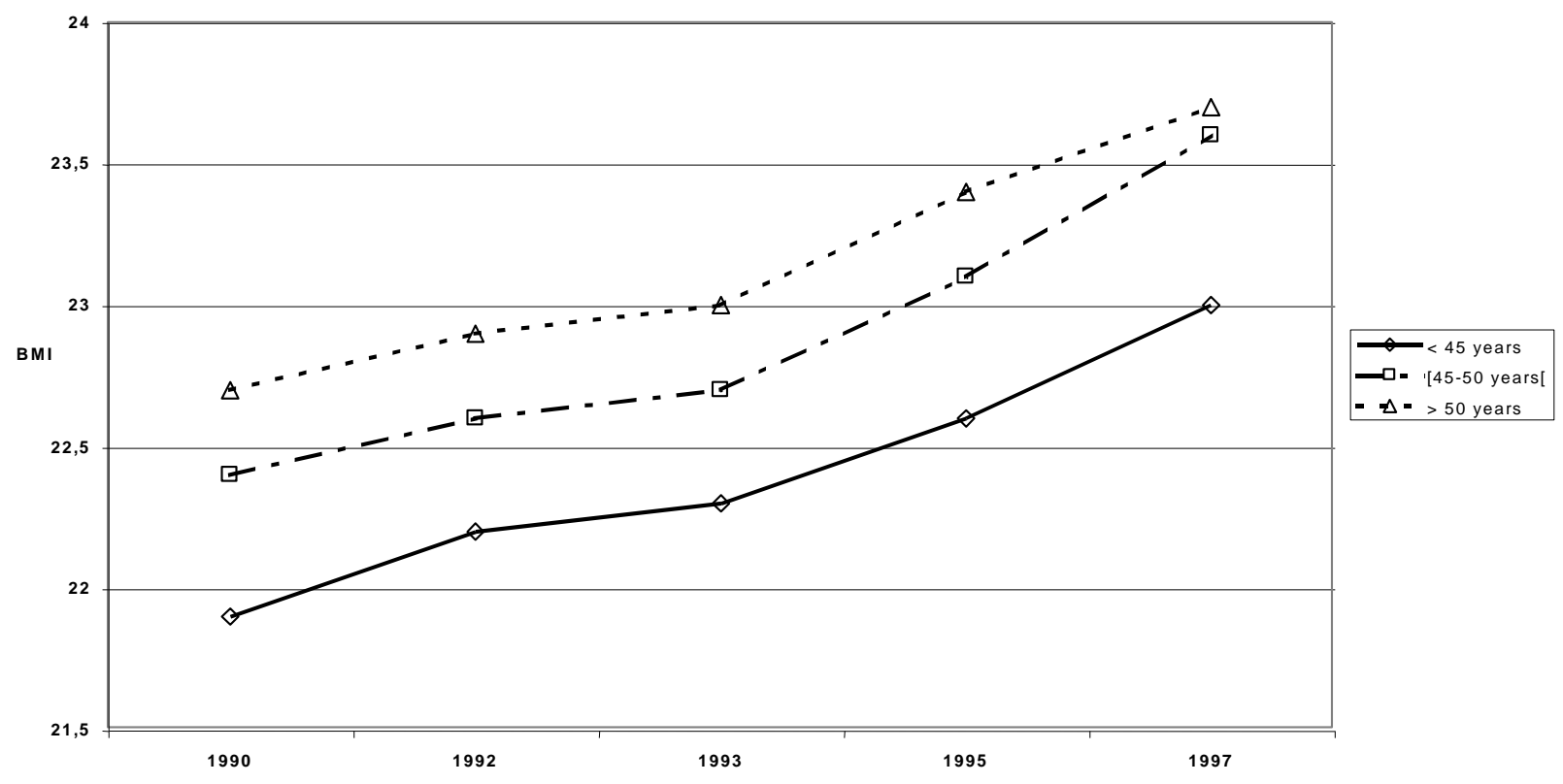


Figure 2: BM I variations during follow -up, according to age categories at inclusion, for postmenopausal women of the E3N cohort.

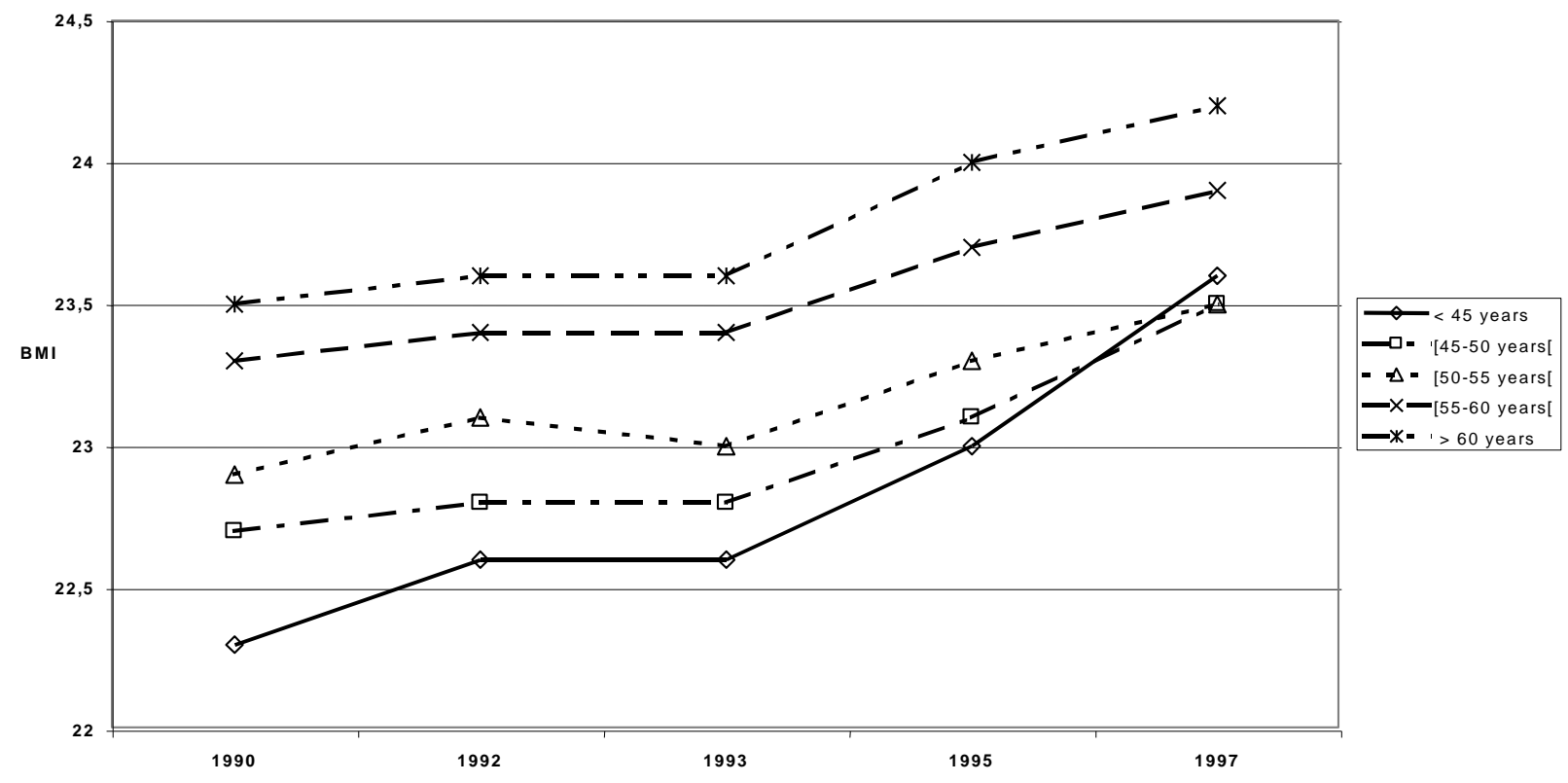

Relative risks of breast cancer associated with weight and BMI as time-dependent variables are shown in Table II. A decrease in risk of premenopausal breast cancer with increasing weight and BMI was observed, though no trend test reached significance (trend $\mathrm{RR}=0.97(0.92-1.01)$ for a $5 \mathrm{~kg}$ increase, trend $\mathrm{RR}=0.96$ (0.91-1.01) for a $2 \mathrm{~kg} / \mathrm{m}^{2}$ increase). Relative risks in the fourth quartile of weight and BMI, as compared to the first, were $0.75(0.61-0.93)$ and $0.78(0.64-0.94)$, respectively. The relative risk of premenopausal breast cancer reached $0.66(0.40-1.10)$ for women with a BMI of over $30 \mathrm{~kg} / \mathrm{m}^{2}$ compared to women with a BMI between 18.5 and $25 \mathrm{~kg} / \mathrm{m}^{2}$.

Significant positive trends of increasing risk of postmenopausal breast cancer with both increasing weight and BMI were observed (trend RR $=1.05(1.02-1.08)$ for weight and trend RR = $1.06(1.02-1.09)$ for BMI, respectively). The RR associated with weight and BMI for the fourth quartile, as compared to the first, were $1.06(0.91-1.21)$ and $1.06(0.93-1.21)$, respectively. Because the cut-offs were defined according to the baseline distribution, the number of subjects in the upper quartile increased during follow-up. We therefore divided it into 2 categories. Higher RRs were observed for the upper categories of weight [over $68 \mathrm{~kg}$ : RR $=1.10$ $(0.93-1.29)$ ] and BMI [over $26.2 \mathrm{~kg} / \mathrm{m}^{2} \mathrm{RR}=1.15(1.00-1.34)$ as compared to the first quartiles]. Women with a BMI of under $18.5 \mathrm{~kg} / \mathrm{m}^{2}$ had a lower risk, of $0.72(0.51-1.00)$, while a RR of $1.23(1.00-1.59)$ was seen in obese women (BMI over $30 \mathrm{~kg} / \mathrm{m}^{2}$ ) as compared to women with a BMI of between 18.5 and $25 \mathrm{~kg} / \mathrm{m}^{2}$.

Interactions between weight or BMI and HRT use were studied in relation to postmenopausal breast cancer occurrence because of a possible differential effect of HRT use in the relation between weight or BMI and breast cancer. HRT use was recorded in each follow-up questionnaire and we considered it as a timedependent variable in our models. Significant positive trend RRs were observed (Table III) in both subgroups (HRT users and HRT neverusers). Trend RRs related to BMI were equal to $1.06(1.01-1.12)$ for HRT users and 1.05 (1.01-1.10) for HRT never users. There was however some indication of a possible effect modification by HRT use, with a weak difference in risk estimates in the highest quartiles of BMI. 
Table II: Relative risks of pre- and post-menopausal breast cancer according to weight and BMI selfreported every two years. E3N cohort (1990-2000).

\begin{tabular}{|c|c|c|c|c|}
\hline Variable & Cases & Total person-years & Multivariate relative risk & Trend RRs ${ }^{1}$ \\
\hline \multicolumn{5}{|c|}{ Premenopausal women } \\
\hline $\mathrm{Q} 1(\leq 52)$ & 153 & 65,0861 & 1.00 (reference) & \multirow[t]{4}{*}{$0.97(0.92-1.01)$} \\
\hline Q2 (52-57) & 173 & 73,041 & $0.86(0.70-1.04)$ & \\
\hline Q3 (57-63) & 202 & 72,236 & $0.96(0.79-1.17)$ & \\
\hline $\mathrm{Q} 4(>63)$ & 164 & 73,180 & $0.75(0.61-0.93)$ & \\
\hline \multicolumn{5}{|l|}{ BMI $\left(\mathrm{kg} / \mathrm{m}^{2}\right)$} \\
\hline $\mathrm{Q} 1(\leq 20.2)$ & 162 & 64,986 & 1.00 (reference) & \multirow{4}{*}{$0.96(0.91-1.01)$} \\
\hline Q2 (20.2-21.6) & 161 & 65,782 & $0.86(0.71-1.05)$ & \\
\hline Q3 (21.6-23.4) & 185 & 71,747 & $0.90(0.74-1.09)$ & \\
\hline Q4 (>23.4) & 184 & 81,028 & $0.78(0.64-0.94)$ & \\
\hline \multicolumn{5}{|l|}{ BMI (kg/m2) } \\
\hline$<18.5$ & 33 & 12,697 & $.06(0.74-1.50)$ & \multirow[t]{4}{*}{2} \\
\hline$[18.5-25]$ & 553 & 225,058 & 1.00 (reference) & \\
\hline$[25-30]$ & 91 & 36,968 & $0.93(0.74-1.16)$ & \\
\hline$\geq 30$ & 15 & 8,820 & $0.66(0.40-1.10)$ & \\
\hline \multicolumn{5}{|c|}{ Post-menopausal Women } \\
\hline \multicolumn{5}{|c|}{ Weight $(\mathrm{kg})$} \\
\hline $\mathrm{Q} 1(\leq 53)$ & 254 & 98,846 & 1.00 (reference) & \multirow{6}{*}{$1.05(1.02-1.08)$} \\
\hline Q2 (53-58) & 297 & 106,508 & $0.95(0.82-1.10)$ & \\
\hline Q3 (58-64) & 331 & 109,358 & $1.02(0.88-1.18)$ & \\
\hline Q4 (> 64) & 429 & 140,395 & $1.06(0.91-1.21)$ & \\
\hline $\mathrm{Q} 4{ }_{1}(64-68)$ & 158 & 54,263 & $0.99(0.82-1.19)$ & \\
\hline $\mathrm{Q}_{2}(>68)$ & 271 & 86,131 & $1.10(0.93-1.29)$ & \\
\hline \multicolumn{5}{|l|}{ BMI $\left(\mathrm{kg} / \mathrm{m}^{2}\right)$} \\
\hline $\mathrm{Q} 1(\leq 20.6)$ & 239 & 87,955 & 1.00 (reference) & \multirow{6}{*}{$1.06(1.02-1.09)$} \\
\hline Q2 (20.6-22.2) & 272 & 96,899 & $0.91(0.79-1.07)$ & \\
\hline Q3 (22.2-24.2) & 331 & 117,463 & $0.95(0.81-1.08)$ & \\
\hline Q4 (>24.2) & 469 & 152,791 & $1.06(0.93-1.21)$ & \\
\hline $\mathrm{Q}_{1}(24.2-26.2)$ & 202 & 70,906 & $0.97(0.81-1.14)$ & \\
\hline $\mathrm{Q}_{2}(>26.2)$ & 267 & 81,884 & $1.15(1.00-1.34)$ & \\
\hline \multicolumn{5}{|l|}{ BMI $\left(\mathrm{kg} / \mathrm{m}^{2}\right)$} \\
\hline$<18.5$ & 33 & 15,135 & $0.72(0.51-1.00)$ & \multirow{4}{*}{2} \\
\hline$[18.5-25[$ & 916 & 320,722 & 1.00 (reference) & \\
\hline$[25-30[$ & 285 & 95,580 & $1.05(0.92-1.20)$ & \\
\hline$\geq 30$ & 77 & 10,943 & $1.23(1.00-1.59)$ & \\
\hline
\end{tabular}

${ }^{1}$ Trend RRs are calculated on a $5 \mathrm{~kg}$ increase in weight and a $2 \mathrm{~kg} / \mathrm{m}^{2}$ increase in BMI. $-{ }^{2}$ The test is identical for both variables on BMI.

Table III: Relative risks of post-menopausal breast cancer according to weight and BMI self-reported every two years in the E3N cohort, by HRT use ${ }^{1}$. E3N cohort (1990-2000).

\begin{tabular}{|c|c|c|c|c|c|c|}
\hline \multirow[t]{2}{*}{ Variable } & \multicolumn{3}{|c|}{ HRT users } & \multicolumn{3}{|c|}{ HRT never users } \\
\hline & $\begin{array}{l}\text { Total (cases) } \\
\text { person-years }\end{array}$ & $\begin{array}{l}\text { Multivariate } \\
\text { relative risk }\end{array}$ & Trend RRs ${ }^{2}$ & $\begin{array}{l}\text { Total (cases) } \\
\text { person-years }\end{array}$ & $\begin{array}{l}\text { Multivariate } \\
\text { relative risk }\end{array}$ & Trend $\mathrm{RRs}^{2}$ \\
\hline \multicolumn{7}{|l|}{ Weight (Kg) } \\
\hline Q1 $(\leq 53)$ & $49,158(135)$ & 1.00 (reference) & & 49,687 (119) & 1.00 (reference) & \\
\hline Q2 (53-58) & 54,540 (157) & $1.00(0.82-1.25)$ & $1.06(1.01-1.11)$ & $51,967(140)$ & $0.90(0.73-1.11)$ & $1.04(1.00-1.09)$ \\
\hline Q3 (58-64) & 54,591 (185) & $1.17(0.95-1.44)$ & & 54,766 (146) & $0.89(0.72-1.10)$ & \\
\hline Q4 > 64 & $58,804(203)$ & $1.19(0.97-1.48)$ & & $81,590(226)$ & $0.94(0.78-1.15)$ & \\
\hline \multicolumn{7}{|l|}{$\mathrm{BMI}\left(\mathrm{Kg} / \mathrm{m}^{2}\right)$} \\
\hline Q1 $(\leq 20.6)$ & 44,463 (122) & 1.00 (reference) & & 43,491 (117) & 1.00 (reference) & \\
\hline Q2 (20.6-22.2) & $50,854(149)$ & $1.02(0.82-1.26)$ & $1.06(1.01-1.12)$ & 46,044 (123) & $0.85(0.68-1.04)$ & $1.05(1.01-1.10)$ \\
\hline Q3 (22.2-24.2) & $58,542(179)$ & $1.06(0.86-1.30)$ & & $58,920(152)$ & $0.83(0.67-1.01)$ & \\
\hline Q4 (>24.2) & $63,234(230)$ & $1.26(1.04-1.54)$ & & 89,556 (239) & $0.90(0.75-1.09)$ & \\
\hline \multicolumn{7}{|l|}{$\mathrm{BMI}\left(\mathrm{Kg} / \mathrm{m}^{2}\right)$} \\
\hline$<18.5$ & 6,894 (12) & $0.56(0.32-0.99)$ & 3 & $8,239(21)$ & $0.88(0.57-1.35)$ & 3 \\
\hline [18.5-25[ & $162,573(500)$ & 1.00 (reference) & & $158,148(416)$ & 1.00 (reference) & \\
\hline [25-30[ & $40,327(140)$ & $1.12(0.93-1.35)$ & & $55,252(145)$ & $1.00(0.82-1.20)$ & \\
\hline$\geq 30$ & $3,323(28)$ & $1.32(0.90-1.95)$ & & $16,372(49)$ & $1.17(0.89-1.57)$ & \\
\hline
\end{tabular}

${ }^{1}$ Considered as a time-dependent variable. Women are in the nonusers group until first use. ${ }^{2}$ Trend RRs are calculated on a $5 \mathrm{~kg}$ increase in

weight and a $2 \mathrm{~kg} / \mathrm{m} 2$ increase in BMI.- ${ }^{3}$ The test is identical for both variables on BMI. 


\section{Discussion}

The results of our cohort study on women aged between 40 and 65 years showed that overweight had opposite effects on breast cancer risk according to menopausal status over a 10-year follow-up period, taking into account weight change prospectively. We found that the risk of premenopausal breast cancer decreased significantly with increasing weight or BMI, that the risk of postmenopausal breast cancer increased with increasing weight and BMI and lastly that the latter increase was similar in HRT users and never users.

\section{Epidemiological concerns}

From the studies published so far, evidence of any negative relationship between premenopausal breast cancer and overweight is unclear. ${ }^{2,4,5,11,12}$ In particular, most results from cohort studies have been nonsignificant. ${ }^{2,4}$ Significance was reached in the Pooling Project on Diet and Cancer, which combined 7 cohort studies, ${ }^{4}\left[\mathrm{RR}=0.90(0.83-0.97)\right.$ for a $10 \mathrm{~kg}$ increase and $\mathrm{RR}=0.89(0.81-0.97)$ for a $4 \mathrm{~kg} / \mathrm{m}^{2}$ increase, respectively]. Our results are lower and consistent with those found in a recent case-control study, ${ }^{11}$ with RRs of $0.81(0.55-1.19)$ and $0.69(0.47-1.02)$ for the last quartiles of weight and BMI, respectively, as compared to the first. Other recent casecontrol studies have found only a weak nonsignificant relation between weight, BMI and premenopausal breast cancer risk ${ }^{12}$ or no significant relation at all between weight, BMI and premenopausal breast cancer. ${ }^{5}$

Our results concerning postmenopausal breast cancer risk showed positive trends in risk with weight and BMI, with RRs slightly lower than in previous studies. ${ }^{2}$ In the Pooling Project on Diet and Cancer, ${ }^{4}$ the trend RRs found (trend $R R=1.06(1.03-1.10)$ for a $10 \mathrm{~kg}$ increase and trend $\left(\mathrm{RR}=1.07(1.02-1.11)\right.$ for a $4 \mathrm{~kg} / \mathrm{m}^{2}$ increase, respectively) were lower than ours. More recently, a case-control study11found no significant relation between postmenopausal breast cancer risk and weight and BMI. Other recent studies have found high risks with overweight: in a Swedish cohort study, Lahmann et al. ${ }^{6}$ found significant increases in risk of postmenopausal breast cancer, with RRs of $1.53(0.97-2.41)$ and 1.54 (1.01-2.35) for the highest quintile of weight and BMI compared to the lowest. Case-control studies on postmenopausal Asian women ${ }^{5,13,14}$ have found an approximate doubling in risk for the highest categories of weight and BMI.

We did not confirm the previous findings concerning an effect of anthropometry on postmenopausal breast cancer limited to HRT never users. ${ }^{2,4-6,15,16}$ Abdominal obesity causes an increase of insulin-like growth factor I (IGF-I) activity and a decrease in sex hormone binding globulin (SHBG) level, which are both risk factors of breast cancer. The use of oral estrogen replacement therapy may balance the increase in breast cancer risk due to obesity by contrasting insulin resistance and inducing an increase in SHBG levels and a decrease in circulating IGF-I activity, ${ }^{17,18}$ thus explaining the stronger association between the use of oral unopposed estrogen replacement therapy and breast cancer among lean women as compared to obese ones. ${ }^{19}$ In our cohort, $78 \%$ of HRT users used a combination of estrogens and progestogens as their main HRT (more than $70 \%$ of total HRT use) and the type of progestogens used (androgenic, whether derived from 19-Nor-Testosterone or not, i.e., pregnane or norpregnane derivatives) may have a different influence on insulin levels, IGF1 activity and SHBG levels, accounting for our results. ${ }^{17,18}$

French women in our cohort are lean as compared to participants of cohort studies in other countries, ${ }^{20}$ and the HRT users among them had a significantly lower weight and BMI than never users $\left(p<10^{-4}\right)$ at the time of reply to each questionnaire. This results in an over-representation of lean women among HRT users and an over-representation of overweight women among HRT nonusers.

Many studies, as reviewed by Friedenreich, ${ }^{2}$ have investigated the potential effect of overweight in breast carcinogenesis. They have found with both pre- and post-menopausal women that obesity is associated with increased plasma concentrations of testosterone and decreased concentrations of SHBG, and as a result of free estrogens. All of these are risk factors for breast cancer and account for the increase found in postmenopausal women. Potischman ${ }^{21}$ observed that serum total estradiol levels decrease with premenopausal obesity, whereas they increase with postmenopausal obesity, which could explain the inverse relation between obesity and breast cancer risk according to menopausal status. In naturally estrogenized premenopausal women, anovulation due to obesity would result in a decrease in estrogen and progesterone production. ${ }^{22-24}$ 


\section{Methodological concerns}

One major problem for prospective studies occurs when anthropometric measurements made at baseline are used to predict a risk of disease occurring several years later. ${ }^{2,25}$ It may create important discrepancies in results between different studies because in women the rate of increase of weight changes over time, especially with age and menopause. E3N is the first cohort study to consider weight and BMI as time-dependent variables with regularly updated data. In our cohort, 24,910 women changed their menopausal status between their enrollment and 2000, during which period 350 cases of postmenopausal breast cancer occurred. For these women, any estimate of their RR of postmenopausal breast cancer, using their weight and BMI recorded before menopause, would have led to misclassification.

Moreover, some studies have found that the risk relation between postmenopausal breast cancer occurrence and anthropometry is higher for older women. ${ }^{4,13,26,27}$ Consequently, anthropometric measurements made at baseline would underestimate the RRs, especially if the disease is distant from baseline. Updating our data regularly reduces the time lag between the latest measurements and breast cancer occurrence.

As recommended by Korn, ${ }^{28}$ we used age as the time scale, which means that women were included with increasing ages in the log-likelihood of our Cox model. In such a model, relative risks are calculated within women of equivalent ages. Moreover if age is used as the time scale, no hypothesis on the log-linearity of age is required. On the contrary, in models using time-on-study as the time scale, with adjustment for age, such a hypothesis on the log-linearity of age may be false if, as previously noted, the risk increases with age. On the other hand, the use of age as the time scale, with women of the same age taken into account in the log-likelihood of the model, may introduce an important bias in the evaluation of relative risks in studies using only anthropometric measurements at baseline, since measurements correspond to different ages in these studies. We were able to avoid these 2 major pitfalls by using models for which the anthropometric measurements were updated during the follow-up.

When considering exclusively weight and BMI at enrollment, RRs of premenopausal breast cancer were closer to unity than those obtained with measurements as time-dependent variables (data not shown). Accurate RRs calculation that would take account of the variation of anthropometric characteristics over time may thus reveal a beneficial effect of overweight in the premenopause more important than usually considered.

RRs of postmenopausal breast cancer associated with measurements at enrollment were of a higher magnitude than those with measurements as time-dependent variables (data not shown). The relatively young age of the E3N postmenopausal participants may in part be responsible for our lower estimates as compared to previous published studies, if the effect of overweight on breast cancer risk increases with age. A longer followup with further assessments of weight and BMI will also improve our understanding of the effect of anthropometry according to HRT use. Part of the previous published results on postmenopausal breast cancer risk may be over-estimated due to less accurate models.

\section{Limitations of our study}

The E3N population is more health-conscious than the general population, with an under-representation of obese women, as compared for example to other European EPIC populations. ${ }^{20}$ As in most large cohort studies, analyses are based on self-reported anthropometric measurements. Many studies have shown that obese subjects tended to under-estimate their real weight. ${ }^{29-37}$ Nevertheless, recent studies have shown good correlations between self-reported anthropometric measurements and measurements made by technicians. ${ }^{38-41}$ We conducted a validation study ${ }^{42}$ on 152 women in the E3N cohort, who self-reported their anthropometric characteristics on a questionnaire before the same characteristics were measured by technicians during a short interview. We found no significant differences between reported and measured values, and correlations between reported and measured characteristics reached 0.89 for height, 0.94 for weight and 0.92 for BMI. We also found that women weighing over $65 \mathrm{~kg}$ had a pessimistic perception of their body shape less often than leanerwomen. However, as a result of the prospective design of our study, this would only bias our results towards unity and would in no way produce significant results.

\section{Conclusion}

Our study gives evidence that overweight decreases premenopausal breast cancer risk and increases postmenopausal breast cancer risk. The relationship might however be more important in premenopausal women 
and less important in postmenopausal women than usually accepted from the literature. Reasons for this discrepancy may come from the capability of our study to take into account variations of anthropometry through life.

When considering only baseline measurements, our results were closer to the literature. Whether this is the consequence of an inadequate modeling of weight variations or whether it is the effect of an increasing effect of overweight with age is debatable.

Our cohort is still ongoing, and a longer follow-up may help to solve this issue. Additional results from cohort studies with repeated measurements of weight are needed. We recommend investigators to analyze these data with careful assessment of variations in weight. A less detrimental effect of overweight on postmenopausal breast cancer risk than usually admitted, and a more marked protective effect before the menopause should not however mask its general unfavorable effects on health.

\section{Acknowledgements}

The authors are indebted to all participants for providing the data used in this study and to practitioners for providing pathology reports. The authors are grateful to all practitioners who collaborate to provide an accurate information. They are grateful to L. Orsi for his help in preparing the data and to G. Evans for his assistance with the English.

\section{References}

1. World Cancer Research Fund/American Institute for Cancer Research. Food, Nutrition and the Prevention of Cancer: a Global Perspective. 1997. 252-88.

2. Friedenreich CM. Review of anthropometric factors and breast cancer risk. Eur J Cancer Prev 2001;10:15-32.

3. IARC Handbooks of Cancer Prevention, Volume 6, Weight Control and Physical Activity. IARC Press, 2002.

4. van den Brandt PA, Spiegelman D, Yaun SS, Adami HO, Beeson L, Folsom AR, Fraser G, Goldbohm RA, Graham S, Kushi L, Marshall JR, Miller AB, et al. Pooled analysis of prospective cohort studies on height, weight, and breast cancer risk. Am J Epidemiol 2000;152: 514-27.

5. Shu XO, Jin F, Dai Q, Rong Shi J, Potter JD, Brinton LA, Herbert JR, Ruan Z, Gao YT, Zheng W. Association of body size and fat distribution with risk of breast cancer among Chinese women. Int J Cancer 2001 Nov 1;94:449 55.

6. Lahmann PH, Lissner L, Gullberg B, Olsson H, Berglund G. A prospective study of adiposity and post-menopausal breast cancer risk: the Malmö Diet and Cancer Study. Int J Cancer 2003;103:246-52.

7. Clavel-Chapelon F and the E3N-EPIC Group. Differential effects of reproductive factors on the risk of pre- and post-menopausal breast cancer: results from a large cohort of French women. Br J Cancer 2002;4:723-7.

8. Riboli E, Hunt K, Slimani N, Ferrari P, Norat T, Fahey M, Charrondière U, H'emon B, Casagrande C, Vignat J, Overvad K, Tjønneland A, et al. European Prospective Investigation into Cancer and Nutrition (EPIC): study populations and data collection. Publ Health Nutr 2002;5:1113-24.

9. WHO Expert Committee. Physical status: the use and interpretation of anthropometry. Geneva, WHO, 1995.

10. Allison PD. Survival analysis using The SAS_System: a practical guide. Cary, NC: SAS Institute, Inc., 1992. 292 pp.

11. Friedenreich CM, Courneya KS, Bryant HE. Case-control study of anthropometric measures and breast cancer risk. Int J Cancer 2002; 99:445-52.

12. Wenten M, Gilliland FD, Baumgartner K, Samet JM. Associations of weight, weight change, and body mass with breast cancer risk in Hispanic and non-Hispanic white women. Ann Epidemiol 2002;12: 435-4.

13. Hirose K, Tajima K, Hamajima N, Takezaki T, Inoue M, Kuroishi T, Miura S, Tokudome S. Effect of body size on breast-cancer risk among Japanese women. Int J Cancer 1999;80:349 -55.

14. Tung HT, Tsukuma H, Tanaka H, Kinoshita N, Koyoma Y, Ajiki W, Oshima A, Koyoma H. Risk factors for breast cancer in Japan, with special attention to anthropometric measurements and reproductive history. Jpn J Clin Oncol 1999;29:137-46

15. Morimoto LM, White E, Chen Z, Chlebowski RT, Hays J, Kuller L, Lopez AM, Manson J, Margolis KL, Muti PC, Stefanick ML, Mc-Tiernan A. Obesity, body size, and risk of post-menopausal breast cancer: the Women's Health Initiative (United States). Cancer Causes Control 2002;13:741-51.

16. Huang Z, Hankinson SE, Colditz GA, Stampfer MJ, Hunter DJ, Manson JE, Hennekens CH, Rosner B, Speizer FE, Willett WC. Dual effects of weight and weight gain on breast cancer risk. JAMA 1997;278:1407-11.

17. Campagnoli C, Biglia N, Cantamessa C, Lesca L, Sismondi P. HRT and breast cancer risk: a clue for interpreting the available data. Maturitas 1999;33:185-90.

18. Campagnoli C, Abbà C, Ambroggio S, Biglia N, Ponzone R. Breast and hormone replacement therapy: putting the risk into perspective. Gynecol Endocrinol 2001;15:53-60. 
19. Collaborative Group on Hormonal Factors in Breast Cancer. Breast cancer and hormone replacement therapy: collaborative reanalysis of data from 51 epidemiological studies of 52705 women with breast cancer and 108411 women without breast cancer. Lancet 1997;350:1047-59.

20. Haftenberger M, Lahmann PH, Panico S, Gonzalez CA, Seidell JC, Boeing H, Giurdanella MC, Krogh V, Buenode-Mesquita HB, Peeters PHM, Skeie G, Hjartaker A, et al. Overweight, obesity and fat distribution in 50-64-yearold participants in the European Prospective Investigation into Cancer and Nutrition (EPIC). Public Health Nutrition 2002;5:1147-62.

21. Potischman N, Swanson CA, Siiteri P, Hoover RN. Reversal of relation between body mass and endogenous oestrogen concentrations with menopausal status. J Natl Cancer Inst 1996;88:756-8.

22. Stoll BA. Impaired ovulation and breast cancer risk. Eur J Cancer 1997;33:1532-5.

23. Stoll BA. Teenage obesity in relation to breast cancer risk. Int J Obes Relat Metab Disord 1998;22:1035- 40.

24. Stoll BA. Perimenopausal weight gain and progression of breast cancer precursors. Cancer Detect Prev 1999;23:31-6.

25. Williamson DF, Kahn HS, Remington PL, Anda RF. The 10-year incidence of overweight and major weight gain in US adults. Arch Intern Med 1990; 150:665-72.

26. Franceschi S, Favero A, La Vecchia C, Baron AE, Negri E, Dal Maso L, Giacosa A, Montella L, Conyi E, Amadori D. Body size indices and breast cancer risk before and after menopause. Int J Cancer 1996;67:181-6.

27. Yong LC, Brown CC, Schatzkin A, Schairer C. Prospective study of relative weight and risk of breast cancer: the Breast Cancer Detection Demonstration Project follow-up study, 1979 to 1987-1989. Am J Epidemiol. 1996, 122:731- 40 .

28. Korn EL, Graubard BI, Midthune D. Time-to-event analysis of longitudinal follow-up of a survey: choice of timescale. Am J Epidemiol 1997;145:72- 80.

29. Kuskowska-Wolk A, Bergstrom R, Bostrom G. Relationship between questionnaire data and medical records of height, weight and body mass index. Int J Obes Relat Metab Disord 1992;16:1-9.

30. Smith GT, Hohlstein LA, Atlas JG. Accuracy of self-reported weight: covariation with binger or restrainer status and eating disorder symptomatology. Addict Behav 1992;17:1-8.

31. Leonhard ML, Barry NJ. Body image and obesity: effects of gender and weight on perceptual measures of body image. Addict Behav 1998;23:31-4.

32. Madrigal H, Sanchez-Villegas A, Martinez-Gonzalez MA, Kearney J, Gibney MJ, Irala J, Martinez JA. Underestimation of body mass index through perceived body image as compared to self-reported body mass index in the European Union. Public Health 2000;114:468 -73.

33. Niedhammer I, Bugel I, Bonenfant S, Goldberg M, Leclerc A. Validity of self-reported weight and height in the French GAZEL cohort. Int J Obes Relat Metab Disord 2000;24:1111-8.

34. Chang VW, Christakis NA. Extent and determinants of discrepancy between self-evaluations of weight status and clinical standards. J Gen Intern Med 2001;16:538-43.

35. Nawaz H, Chan W, Abdulrahman M, Larson D, Katz DL. Selfreported weight and height: implications for obesity research. Am J Prev Med 2001 May;20:294-8.

36. Kuczmarski MF, Kuczmarski RJ, Najjar M. Effects of age on validity of self-reported height, weight, and body mass index: findings from the Third National Health and Nutrition Examination Survey, 1988-1994. J Am Diet Assoc 2001;101:28-34.

37. Rossouw K, Senekal M, Stander I. The accuracy of self-reported weight by overweight and obese women in an outpatient setting. Public Health Nutr 2001;4:19 -26.

38. Davis H, Gergen PJ. Self-described weight status of Mexican-American adolescents. J Adolesc Health 1994;15:407-9.

39. Davis H, Gergen PJ. The weights and heights of Mexican-American adolescents: the accuracy of self-reports. Am J Public Health 1994; 84:459-62.

40. Weaver TW, Kushi LH, McGovern PG, et al. Validation study of self-reported measures of fat distribution. Int J Obes Relat Metab Disord 1996;20:644 -50.

41. Klipstein-Grobusch K, Georg T, Boeing H. Interviewer variability in anthropometric measurements and estimates of body composition. Int J Epidemiol 1997;26:S174-80.

42. Téhard B, van Liere M, Com-Nougue C, Clavel-Chapelon F. Anthropometric measurements and body silhouette of women: validity and perception. J Am Diet Assoc 2002;102:1779-84. 